\title{
Os antigos cafés do Recife: a sociabilidade na capital pernambucana $(1920-1937)^{*}$

\author{
The old cafes of Recife: sociability in capital \\ of Pernambuco (1920 - 1937)
}

\section{Carlos André Silva de Moura}

Doutorando em História na Universidade Estadual de Campinas (Unicamp) e bolsista da Fundação de Amparo à Pesquisa do Estado de São Paulo (Fapesp)

casmcarlos@yahoo.com.br

\section{Resumo:}

As memórias são instrumentos fundamentais para a produção historiográfica. Desde as biografias, os diários e os depoimentos, percebemos o quanto as fontes têm contribuído com as discussões sobre as diversas temáticas, demonstrando especificidades que náo podem ser vistas em outras formas de documentação. É a partir de tal abordagem que analisaremos alguns cafés e bares do Recife como espaços de sociabilidade nas primeiras décadas do século XX, observando os debates sobre o cotidiano, suas avaliações políticas e culturais, a divulgação de notícias, as festas e as transformaçóes do espaço citadino.

Palavras-chave: Memórias; Espaços de sociabilidade; Intelectuais

\section{Abstract:}

Memories are key tools for historical production. From the biographies, diaries and interviews, we realized how the sources have contributed to discussions on various topics, demonstrating specificities that can not be seen in other forms of documentation. It is from such approach that we will analyze a few cafes and bars of Recife as spaces of sociability in the early decades of the twentieth century by observing the discussions about everyday life, their political and cultural assessments, the spreading news, the parties and the transformations of space city.

Keywords: Memory; Spaces of sociality; Intellectuals

\footnotetext{
* Trabalho apresentado no GT Memória e Cidade
} 


\section{Artigos \& Ensaios}

"O viajante que chega ao Recife não é recebido por uma cidade escancarada à sua admiração. Quem vem do Rio ou da Bahia, cidades cenográficas, fotogênicas, um ar sempre em dia de festa, talvez fique desapontado com o Recife. [...] Seu melhor encanto consiste mesmo em deixar-se conquistar aos poucos."

Gilberto Freyre

1 - No início do século $X X$, muitos espaços que se denominavam de Cafés, também funcionavam como bar. No entanto, durante o texto vamos apenas fazer a referência como Cafés, seguindo a narrativa do documento em discussão.
P ensar os espaços de sociabilidade no Recife do início do século XX exige escolhas. A vasta oferta de lugares para as reuniōes de intelectuais, estudantes, políticos, funcionários públicos, jornalistas e outros personagens que formavam a capital pernambucana, impede-nos de fazer uma análise geral. Por este motivo, em nosso texto debatemos sobre alguns espaços que estavam localizados nos bairros de São Antônio, São José e Boa Vista, área central da cidade. Nossas escolhas facilitarão a visualização dos leitores, podendo acompanhar os passos da intelectualidade que no momento debatia sobre as questóes políticas, culturais, sociais entre outras temáticas que estavam em voga no Brasil.

Debruçamos-nos sobre as produçôes do ambiente citadino, por ser um lugar de portas abertas para que possamos compreender os espaços públicos, as discussões culturais, as sensibilidades dos seus personagens. Com a nossa análise foi possível perceber "as vozes que expressam muitas vezes a vontade de liberdade, de uma vida liberta da opressão cotidiana” (BRESCIANI, 1992: 13).

Para apresentação da cidade, observamo-la a partir dos escritos de memorialistas, focalizando o tema da sociabilidade dos intelectuais, por estarmos dedicados ao estudo sobre a temática há algum tempo. Em nossa dissertação, analisamos como os estudantes do Recife mantiveram um debate sobre as questôes político-sociais no Café Lafayette, percebendo como o lugar foi fundamental para a formação de ideias entre os anos de 1930 e 1937 (MOURA, 2010: 63). Atualmente, os nossos estudos estáo concentrados nos debates sobre a Restauraçáo Católica entre os homens das letras portugueses e na capital pernambucana, entre os anos de 1910 e 1937, compreendendo como se desenvolveram as trocas culturais entre os personagens. Para isso, analisamos alguns espaços de sociabilidade no mundo luso-brasileiro, avaliando os meios de divulgaçáo dos debates promovidos para a valorizaçáo das propostas de um Estado sacralizado.

A ideia para a escrita de um artigo sobre os lugares de vivências no Recife, focalizando os cafés e bares[1] da cidade, surgiu de uma pesquisa realizada no jornal Diario de Pernambuco de 1933. Durante a coleta das fontes, encontramos um texto do escritor Mario Sette, onde trabalhava o cotidiano da cidade e a movimentação dos intelectuais nos cafés desde 1900. Sendo assim, a partir dos relatos do memorialista, tivemos o interesse de refletir como esses espaços foram importantes para a sociabilidade dos homens das letras do início do século XX na capital pernambucana.

Mario Sette nasceu no Recife em 19 de abril de 1886. Fez parte do grupo de letrados que mantinha debates com Gilberto Freyre, Joaquim Cardoso, Rachel de Queiroz e Monteiro Lobato, com quem dialogou sobre publicaçōes de artigos em revistas e jornais. Em 1917 publicou seu primeiro livro, Ao Clarão dos Obuses, contos inspirados em episódios da primeira guerra mundial. Em 1922, foi eleito membro da Academia Pernambucana de Letras, ocupando a cadeira de número 40 (Cf. ALMEIDA, 2000). 
Entre as obras do autor, destacamos suas memórias e romances sociais. Em seus textos temos a oportunidade de perceber o Recife do final do século XIX e início do XX, destacando temas como a modernização, as festas, os lugares de sociabilidade, os debates intelectuais e as transformaçóes desenvolvidas no espaço urbano. Nos textos memorialísticos, com suas experiências de vida, os acontecimentos da infância, as rodas de debates e os personagens com quem manteve contato em suas andanças, Mario Sette apresenta-nos um Recife que dificilmente encontramos nas páginas dos periódicos do momento pesquisado. Em seus livros, entramos em contato com os carregadores de pianos, os vendedores de caranguejos e ostras, os comerciantes, os estudantes, os mendigos de gravata e os funcionários públicos que circulavam na cidade.

Com a obra de Mario Sette, temos a oportunidade de perceber os sentimentos, os cheiros e os sabores que circulavam na capital pernambucana. No espaço privado, o autor abre as portas para que o leitor tenha contato com as conversas, o preparo dos alimentos nas festas juninas, o costurar das roupas e os sonhos de jovens e adultos. No público, Mario Sette convida o leitor para arruar[2] entre ruas e becos de uma cidade que se modernizava. Com sua leitura, percebemos os debates nos espaços de sociabilidades, as discussóes dos estudantes da Faculdade de Direito do Recife (F.D.R), o comércio nas lojas e entre os vendedores informais. O tema da modernização é muito presente nos escritos do autor, como podemos perceber em Os Azeredos do Poço, fazendo com que entendamos as transformaçóes urbanísticas da cidade.

Os escritos do memorialista retrataram os debates sobre as reformas na capital pernambucana, o "bota abaixo" na área portuária, abrindo espaços para as largas avenidas, a destruição dos casarios no bairro de Santo Antônio e São José para a passagem da Avenida Dantas Barreto, a retirada das famílias das áreas centrais para que o Estado pudesse efetivar a "limpeza" do espaço urbano. Em seus escritos estão materializados o sentimento de perda dos intelectuais contrários às obras de modernização, destacando a saudade de uma cidade que se foi.

Os discursos de modernização do início do século XX não incorporavam os homens das letras que enxergavam um Recife que deveria manter suas estruturas históricas. Tais afirmaçôes nos remetem aos escritos de Ítalo Calvino, quando chama atenção que "jamais se deve confundir a cidade com o discurso que a descreve" (CALVINO, 1990: 59). Os discursos da capital pernambucana tentavam descrever o moderno que estava sendo implementado nas principais cidades do Brasil, contrário à manutenção das tradiçôes de cidade colonial, defendida por alguns letrados.

Como colaborador do Diario de Pernambuco, Mario Sette trabalhou as questóes de sua atualidade, apresentando os lugares de sociabilidade da intelectualidade, as obras de modernização que "tirava a magia" do Recife, os ensaios e festas que aconteciam nos bairros de São José e da Boa Vista. O memorialista soube compreender o Recife, que se deixou encantar por suas histórias, decifrando o "namoro" proposto por Gilberto Freyre. Para o sociólogo, a capital pernambucana era uma cidade que não:

[...] se entrega imediatamente: seu melhor encanto consiste mesmo em deixar-se conquistar aos poucos. É uma cidade que prefere namorados sentimentais a admiradores imediatos. [...] Muitos saem do Recife com a impressão única, monótona, das ruas claras, batidas de
2 - A palavra Arruar, que deu título à obra de Mario Sette, tem significado de andança ou caminhada por ruas de uma cidade. (Cf. SETTE, 1952). 
sol, das pontes modernas, da gente quase tôda morena

(FREYRE, 1934: 03-05).

Compreendemos a cidade como lugar de possibilidades, de encontros e desencontros, transformaçóes, espaços labirínticos, de desejos e memórias (CALVINO, 1990: 28). Como Mario Sette observou em sua obra, a cidade apresenta-se em constante mudança, com a colaboração dos personagens que a formam, aglutinando novos indivíduos em debates e experiências diversas. As trocas de conhecimento são constantes em espaços de vivências. De tal modo, a sociabilidade opera-se por relaçóes de compartilhamento socioculturais e simbólicas em espaços significativos para os indivíduos, como os lugares de trabalho e recreio, dos lazeres ou do entretenimento, como ruas, parques, praças, cafés, clubes e salóes.

A rua foi um local importante para compreendermos tais relaçóes sociais na cidade. Destacamos que enxergamos a rua como um espaço complementar dos lugares que observamos em nosso texto, onde se poderia acontecer trocas culturais importantes para os debates nos espaços de sociabilidade. A rua "é um fator da vida das cidades, a rua tem alma! Em Benarés ou em Amsterdá, em Londres ou em Bueno Aires, sob os céus mais diversos, nos mais variados climas, a rua é a agasalhadora da miséria” (RIO, 2008: 29-30), lugar de possibilidades diversas.

No momento, estamos pensando a sociabilidade entre os intelectuais no Recife, tomando como espaço os cafés dos bairros centrais. Para Ângela de Castro Gomes, os lugares foram de fundamental importância para a formação cultural dos letrados, para o reconhecimento dos seus pares e a partilha de ideias que conduziram os debates com temáticas variadas. Os espaços frequentados por homens das letras situavam-nos politicamente, formando redes de contatos que os inseriam no mundo cultural (GOMES, 2004: 51).

Destacamos que os intelectuais do início do século XX foram classificados como homens engajados, atuantes no cenário nacional, com propostas em várias áreas sociais. Suas experiências, como literatos, bacharéis, funcionários públicos ou jornalistas, eram compartilhadas nas mesas de muitos cafés, que em alguns momentos se tornaram o segundo escritório para a produção intelectual (Cf. MICELI, 2001).

Em seu texto "Os antigos cafés do Recife", Mario Sette demonstrou como os espaços de sociabilidade foram importantes para a movimentação na cidade no período da noite. Para o autor, entre as décadas de 1910 e 1930, a cidade noturna passou a tomar novas paisagens, com o movimento dos boêmios que circulavam de um bairro para outro. Em seus escritos, destacou que "Morria muito cedo a vida do Recife ainda por volta de 1900. Mal o comercio cerrava as portas - a principio as 9 , depois ás 8 da noite, as ruas tomavam um aspecto de abandono, de solidão, de logar mal afamado" (SETTE, 1933). Nesse instante, o autor oferece especial atenção ao espaço da rua, observando suas mudanças e o ritmo de seus ocupantes durante a noite.

Gilberto Freyre também refletiu sobre a movimentação na cidade do Recife durante a noite nas primeiras décadas do século XX. Comparando a movimentação no Pátio de São Pedro durante as várias horas do dia, destacou que à noite o lugar se tornava o mais desértico da cidade. Caracterizado pelo conjunto arquitetônico formado pela Igreja de São Pedro dos Clérigos e os casarios, o espaço no período noturno "é de pouco movimento. Depois das nove da noite é um dos lugares 
no Recife, em que se pode estar mais só [...]”, durante o dia, o pátio tem uma nova paisagem. "[...] Os carregadores de açúcar da praia de Santa Rita, muito suados, de braços nus e musculosos, de manés-joóes melados, [saboreiam] refresco de abacaxis; a preta dos bolos, habitual da esquina da Rua do Fogo, [expóe] o tabuleiro envidraçado cheio de máes-bentas, cocorotes, pastéis de nata, mata-fomes, [...] á espera da freguesia acostumada." O cenário é constituído por diversos personagens, os "Soldados da polícia [grelam] raparigas de pixains alvoroçados. Um cavalo, à porta de uma vendola, já livre dos sacos de carvão que trouxera, [bate] constantemente com as patas no calçamento, num afugentar das moscas que [teimam] em pousar-lhe num flanco ensangüentado." (FREYRE, 2004: 08).

Rogério Proença Leite destacou a divisão entre o dia e a noite para os espaços de sociabilidade. Antes do uso da energia elétrica, as atividades de lazer muitas vezes limitavam-se aos horários que ainda contavam com a luminosidade solar. No entanto, com o serviço de iluminaçáo 24 horas, com "o dia artificial”, os divertimentos prolongavam-se, as discussōes puderam alongar-se por horas, sendo controladas apenas pelo horário social (LEITE, 2007: 241). Com a iluminação na cidade do Recife, as ruas que ficavam desérticas logo nos primeiros horários em que o sol se despediam, passou a ser frequentadas por personagens que não se contentavam com os debates realizados durante o dia, ou que não tinham a oportunidade de marcar presenças nas discussões diurnas.

O espaço noturno tomava má fama por diversos motivos, inicialmente devido ao cenário que era construído, com "os lampiôes de iluminação pública, [que] em parte, eram apagados. Vinha um velhinho com uma vara comprida e haja a extinguir os pobres bicos em ter que, já por ser minguados, anêmicos. Tudo tomava ar de aposentos onde as lamparinas convidam ao sono" (SETTE, 1933). A imagem contrastava com o comércio diurno, os vendedores a gritar pela melhor promoção na Rua Nova, as casas de corte e costura lotadas por senhoras e suas filhas, que se atualizavam com os novos modelos vindos de Paris. As sorveterias com os estudantes da Faculdade de Direito do Recife, ao pé do balcáo acompanhando o movimento dos bondes que traziam novos personagens ao centro. A noite também tinha má fama devido aos "problemas" causados no Bairro do Recife. Lugar em que os homens procuravam os prazeres sexuais, eram comuns as notícias policiais que se desdobravam na Rua da Guia ou da Madre de Deus, contrastando com o projeto de ordem e moral implementado nas décadas de 1930 e 1940.

$\mathrm{Na}$ Rua Nova também estavam as sorveterias Cristal e Biju, cinemas e teatros que mantinham suas apresentaçóes ao som das orquestras, bem frequentados por parte dos estudantes. O cinema Royal, divulgava quase diariamente sua programação, propagando entre os leitores dos jornais os "filmes que arrepiavam o Recife em Pezo!" (Diario de Pernambuco, 1934). A rua, também, contava com a Livraria do Nogueira, que atendia acadêmicos de várias regióes, era respeitada por oferecer inúmeros exemplares da literatura européia. Os livros jurídicos, também, tornaram-se especialidade da casa, o que ajudou na frequência de membros da F.D.R. no local (PARAÍSO, 2006: 136).

Após o movimento diário na Rua Nova, localizada no Bairro de Santo Antônio, os:

Maridos que tinham lojas apressavam-se [...] para casa, evitando cenas de ciúmes, pelo retardo; rapazes de pais severos também largavam as conversas com as pequenas rumavam o tecto da familia com receio do caráo ou da porta fechada. As boleiras que se estendiam pela praça 


\section{Artigos \& Ensaios}

3 - O Bairro de São José ficou conhecido com o berço dos Blocos Líricos no Recife dos anos de 1920. (Cf. SANTOS, 2010.) da independência repunham os taboleiros na cabeça, enfiavam nos ombros o tamborete e iam caminhando devagar para as bandas de São José (SETTE, 1933).

À noite restava apenas o movimento dos Cafés e bares. Muitas vezes, escutava-se o som dos ensaios dos blocos carnavalescos, vindos do Bairro de São José. Após uma cerveja, alguns resistentes da vida noturna caminhavam até a Rua dos Prazeres, no Bairro da Boa Vista, ou as ruas do Bairro de São José para acompanhar os acertos das marchas dos blocos líricos. Perto das casas que sediavam as agremiaçóes, aproveitava-se para realizar o comércio, que tinha lucro garantido. Os ensaios contavam com a presença de estudantes e trabalhadores, que ao término do expediente, se arriscavam nos passos do frevo ou nos instrumentos musicais[3].

Na Rua Nova [Figura 1] funcionavam os cafés Rui e o Familiar, um de frente para o outro. Durante à noite, eram os únicos lugares de onde saíam luzes, sempre mantendo um movimento dos "Retardatarios a sorver um gelado de maracujá ou a emborcar mais um copo de cerveja”. O Café Rui era o preferido dos estudantes da Faculdade de Direito, com suas mesas redondas de tampo de mármore, os futuros bacharéis faziam "brindes algazarras, bolindo com quem passava. Durante o dia espiavam as pernas das moças quando subiam nos bondes" (SETTE, 1933). Era prática das casas comerciais disponibilizarem atrativos para seus clientes. Jogos, charutaria, salóes de danças e músicas eram as formas de aumentar a clientela, garantindo a maior permanência daqueles que mantinham o divertimento no centro da cidade.

Alguns cafés disponibilizavam um espaço nos andares superiores para o divertimento masculino, com mulheres de nomes europeus e sotaques treinados previamente, atraíam o público de diversas regióes. Deste modo, alguns cafés foram vistos como um reduto de homens, onde a frequência de mulheres de "boa família" não era bem vista.

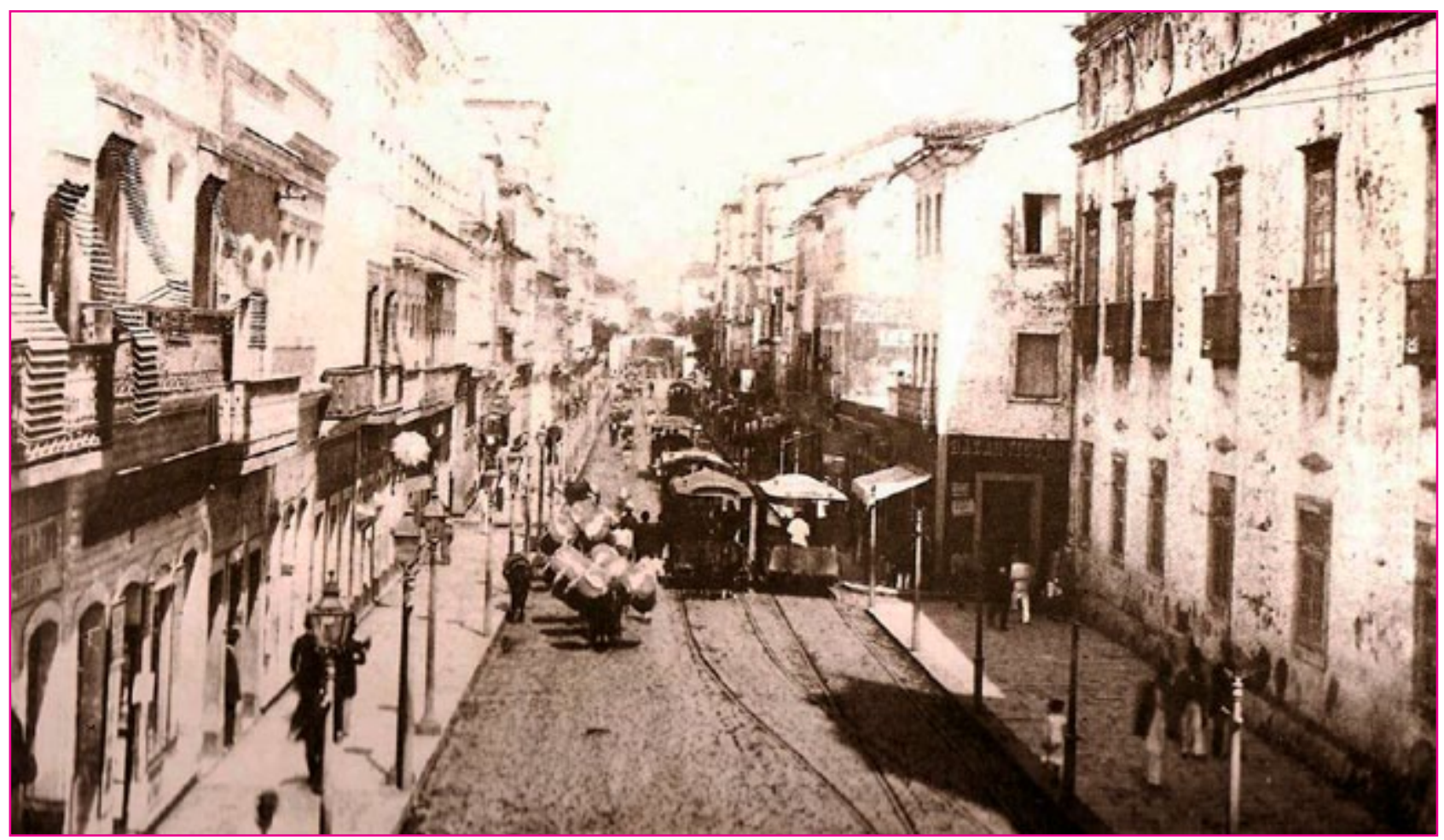

Figura 1 - Rua Nova. Acervo digital da Fundação Joaquim Nabuco - FUNDAJ. S/d. 
Para os pensadores que faziam a vida no Bairro da Boa Vista, os cafés preferidos eram o Santos do Dumont e o Modelo, localizados na Rua da Imperatriz. Uma das principais atraçóes do lugar era o Bozó[4], que tinha a finalidade de decidir o responsável pelo pagamento da conta. O lugar era estratégico para os estudantes que saiam das aulas na Faculdade de Direito ou residiam em ruas próximas do local, como as Ruas Velha, da Glória, dos Prazeres, Pátio de Santa Cruz, até as regióes mais distantes. Os lugares, também, eram próximos a outros centros de estudo, como as Faculdades de Engenharia e Medicina, facilitando as reunióes dos estudantes, sendo considerado um lugar para os debates e açôes estudantis.

No Bairro de Santo Antônio, a Rua do Imperador era enigmática para os intelectuais. No lugar estavam as sedes dos principais jornais que circulavam na cidade, como Jornal do Commercio, Jornal do Recife, Jornal Pequeno, Diario da Manhã e um pouco mais afastado o Diario de Pernambuco. Os pensadores que ali chegavam tomavam informação das notícias que eram fixadas nas paredes das redaçóes, sendo comentadas com os jornalistas no momento de folga nos bares e cafés que ficam ali por perto (PARAÍSO, 2001: 125).

$\mathrm{Na}$ Rua do Imperador funcionava o Café 15 de Novembro, ou o Café do Girão, como era mais conhecido. A sua organização atraía letrados de diversos setores, que eram premiados com o bom atendimento do Sr. Giráo, proprietário do estabelecimento. O Café "Estendia mesinhas e cadeiras pela ampla calçada, ponto preferido dos políticos durante o dia, dos jornalistas, estudantes, rapazes á noite" (SETTE, 1933). Às 19 horas o movimento aumentava com os debates que tinham como lugar preferido a mesa redonda de mármore. Com o passar das horas, a empada e o café sediam espaço para a cerveja e os petiscos, preparados conforme os pedidos dos frequentadores, servidos ainda quentes pelos garçons que também "ousavam" colaborar com as discussóes tão inflamadas. Nas palavras de Mario Sette, fazia-se do "'15' um meio ponto de ligaçáo, de palestra, de gracejos, de outras cousas inocentes para a idade...” (SETTE, 1933).

No espaço debatia-se sobre os acontecimentos nacionais, como a revolta da vacina, as eleiçóes, os movimentos patrióticos, dentre outros assuntos que embalavam os fregueses por horas. No entanto, o local também era usado apenas para os encontros passageiros, principalmente nos dias de espetáculos no Teatro de Santa Isabel. Nosso memorialista destacou, que "Quando havia companhia no Santa Izabel, dali partíamos ás 8 horas, formidavelmente de endumentaria, cheirando a [...] 'Jeanette', numa pose que trazia sorriso, nosso querido Girão: porque ele sabia que íamos direitinho para o paraizo" (SETTE, 1933).

No encontro da Rua do Imperador com a Primeiro de Março estava o Café Continental, mais conhecido como o Café Lafayette[5]. Nas décadas de 1920 e 1930, os diversos assuntos fervilhavam no lugar. Personagens de várias regiôes procurando o Lafayette pelas notícias de um espaço que reuniam os principais nomes da intelectualidade e servia a "melhor coalhada da região". A Revista Ilustração Brasileira classificou o lugar como ambiente de "reunião de políticos, corretores, desoccupados e toda a variada flora e fauna de maldizentes". Ainda segundo o periódico, as colunas jornalísticas que levavam o nome do Café colaboravam com sua fama, ainda sendo privilegiada com o "poste da rede aerea da Tramways" em sua calçada e pelos "já celebres boletins, mais ou menos rubros de que tem sido innocente supporte" para as notícias de seu cotidiano (Ilustração Brasileira, 1924: 199).
4 - Bozó é um jogo composto de copos e dados, onde os jovens apostavam a sorte em suas rodadas.

5 - O Café Continental estava localizado no mesmo prédio do depósito dos cigarros Lafayette, por isso o espaço ficou mais conhecido como Café Lafayette. 


\section{Artigos \& Ensaios}

Vivenciada por jornalistas, políticos e estudantes, que muitas vezes saiam das aulas para discutirem os problemas sociais enfrentados pela população, como o período entre guerras e a falta de assistência do governo, a esquina da Rua do Imperador tornou-se referência entre os jovens. Souza Barros destacou a participação efetiva desses indivíduos, insuflando as discussóes com informaçóes dos debates que aconteciam na Faculdade de Direito. Para o autor, a participação de "Otacilio Alecrim, mais tarde, diretor da revista do Diretório da Faculdade de Direito. E, já na última fase, no período de 1930, os jornalistas Nilo Pereira e Esmaragdo Marroquim" (BARROS, 1972: 212) foram fundamentais para a formação do assíduo grupo de intelectuais da instituição, que se tornaram os debatedores mais exaltados da esquina.

No fragmento abaixo percebemos como se dava a funcionalidade do Café Lafayette [Figura 2] e seus principais frequentadores. O lugar agregava diversas camadas sociais, sendo o Lafayette o Café:

[...] mais importante do Recife até hoje. Café sentado, como se dizia, desses que foram abolidos porque, mais do que dinheiro na caixa, rendiam conversa fiada aos proprietários. [...] Aí, durante anos e anos, discutiram-se, da manhã à noite, entre cafezinhos e baforadas, problemas pernambucanos de toda a espécie. Negócios de compra e venda, futebol, literatura, fuxicos, acerto ou desacerto de casos políticos. O Lafayette era freqüentado por usineiros, deputados, cabos eleitorais, médicos, literatos, comerciantes, estudantes, jornalistas, até governadores (MOTA, 1971: 47 - 48).

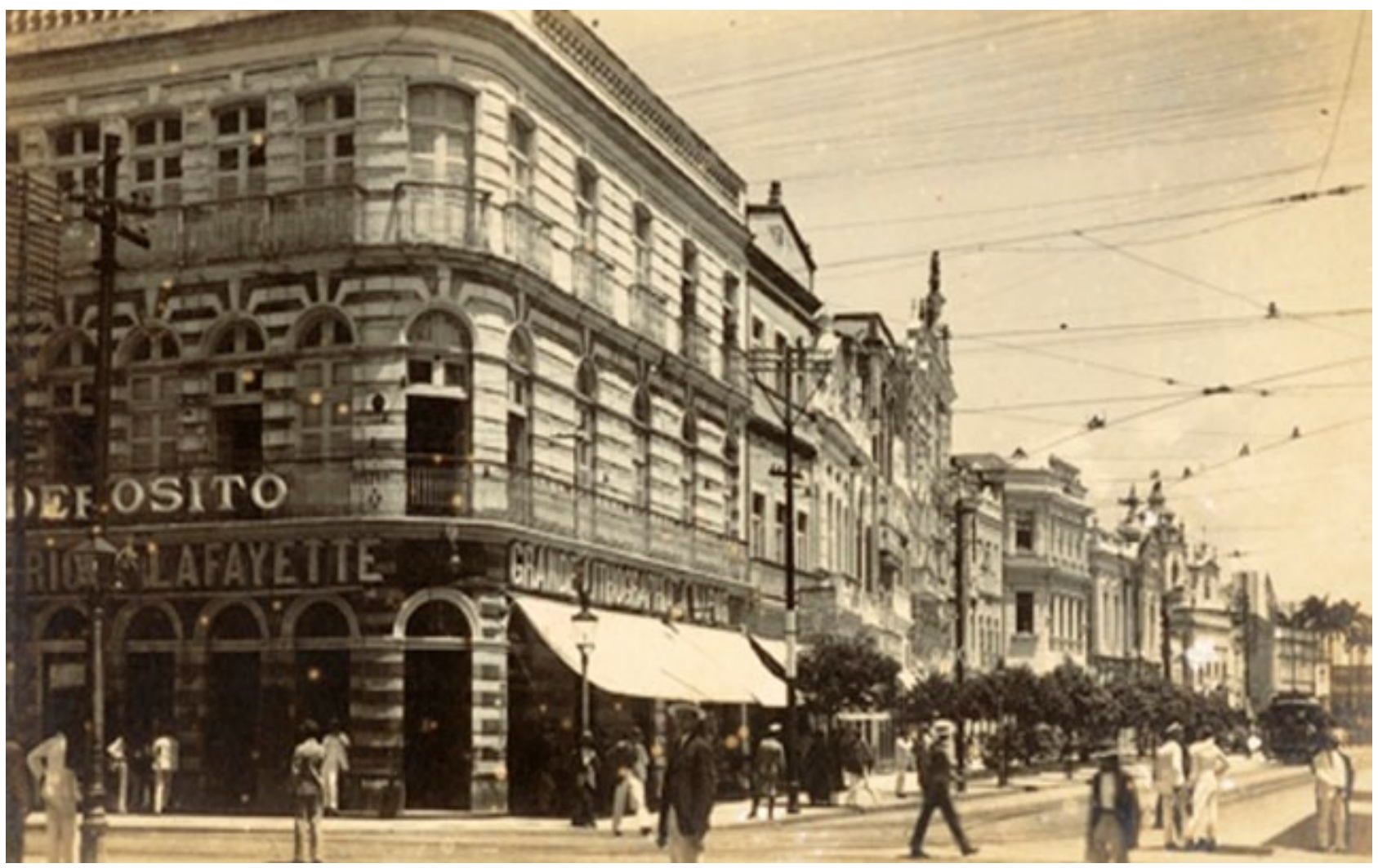

Figura 2 - Fachada do Café Lafayette: Esquina da Rua do Imperador Pedro ll com a Rua $1^{\circ}$ de Março. Acervo digital da Fundação Joaquim Nabuco - FUNDAJ. S/d. 
$\mathrm{Na}$ Praça da Independência, o Café Chile era um lugar destinado às pessoas com maior poder aquisitivo. Seus anúncios demonstravam a sofisticação que o diferenciava dos outros espaços da cidade, com instalaçóes modernas e um atendimento especial. Com uma orquestra que animava o público até por volta das duas horas da manhá, que poderiam se servir dos cigarros e charutos comercializados na tabacaria no interior do estabelecimento. Diferentes de outros ambientes, seu cardápio não estava resumido ao café, à cerveja, à coalhada ou a empada, mas contava com refeiçóes sofisticadas, como a macarronada italiana e bebidas para todos os gostos, como whisky, cervejas importadas e champagne (COUCEIRO, 2007: 07).

$\mathrm{Na}$ Praça da Independência, os frequentadores do Café Chile também contavam com as casas de aposta dos páreos do Jockei Club de Pernambuco. Os serviços, também, eram estendidos para aqueles que tentavam a sorte nos jogos de futebol, com destaques para os clássicos de domingo no campo do Bairro do Derby. O Clube Náutico Capibaribe, o Sport Club do Recife, o América Futebol Clube e o Santa Cruz Futebol Clube eram as principais potências do esporte no período. Aos domingos os campos lotavam, os resultados das partidas eram debatidos nas mesas dos bares e café dos bairros centrais, movimentando o recife com torcedores das diversas "cores".

Os debates que aconteciam nos lugares aqui apresentados náo se reduziam aos espaços frequentados apenas por intelectuais, mas por indivíduos que circulavam pelas ruas, em rodas de conversas que proporcionavam a sociabilidades das discussóes travadas por homens das letras. Por esse motivo, consideramos interessante fazer as análises juntos com as memórias, pois, assim, temos a oportunidade de "ouvir" os diálogos nos diversos lugares da cidade, as discussóes entre os vendedores, os engraxates e os comerciantes, despertando desse modo as histórias que dormem nas ruas (CERTEAU, 2008: 201).

O espaço da rua foi por muito tempo negado entre os pesquisadores na academia, momento em que a História concentrava seus estudos aos grandes fatos e os espaços considerados da elite. Porém, percebemos o ambiente como de fundamental importância para observarmos o reflexo dos debates dos letrados no início do século XX. A rua que já foi mal afamada, "constituía um pecado tão feio! Rua tinha saibo de cousa proibida e de má fama. Moleque de Rua... Povo da Rua... Mulher de Rua... [...]" (SETTE, 1952: 08), porém como nos falou Mario Sette, arruar é gostoso, proporciona descobertas e sensaçóes que transformam nosso olhar sobre a cidade. "A rua se torna moradia para" (BENJAMIN, 1989: 35) aqueles que querem compreender as tensóes de um lugar, mergulhando em seus labirintos, que fazem compreender parte da História do Recife.

Assim como as notícias dos Cafés estavam presentes nas principais páginas de vários jornais, seu perigo, também, era anunciado em algumas seçôes policiais. Alguns cafés foram vistos como lugares perigosos para a ordem e para as mulheres de "boa família". Na esquina do Lafayette, as senhoras evitavam passar por sua calçada, na tentativa de fugir das cantadas disparadas pelos jovens estudantes, que ficavam à espera na porta do estabelecimento. No passar do bonde, ou no caminho para as missas no Convento Franciscano, as mães orientavam as filhas a virarem o rosto para não compartilharem dos gracejos, que eram disparados das mesas do lugar.

A boemia era um costume dos indivíduos das cidades que se diziam modernas, mentes pensantes e fervilhantes que debatiam no centro, local que con- 
centrava os maiores acontecimentos da região, a capital para onde corriam os principais pensamentos de contestação social. Ideias que inspiravam os leitores mais atentos. "Momento do despertar das fantasias, liberdades e açóes que aguçavam o inconsciente de muitos que pensaram a política e a cultura no início do século XX no Recife” (SEIGEL, 1992: 81, 83).

Em seu texto "Os antigos cafés do Recife", Mario Sette apresentou as possibilidades de um Recife em mudança, que vivenciava as transformaçôes das questôes culturais, constantemente debatidas em espaços informais. Com a leitura do seu artigo, foi possível perceber parte do cotidiano boêmio dos jovens letrados na região central da cidade, seus lugares, as temáticas de discussóes e as formas de sociabilidade. Desse modo, reafirmamos a importância dos usos das memórias como fonte para a produção historiográfica.

\section{REFERENCIAS BIBLIOGRÁFICAS}

ALMEIDA, Magdalena. Mário Sette: o Retratista da Palavra. Recife: Fundação de Cultura da Cidade do Recife, 2000.

BARROS, Souza. A Década de 20 em Pernambuco (Uma Interpretação). Rio de Janeiro, 1972.

BENJAMIN, Walter. Charles Baudelaire um Lírico no Auge do Capitalismo: Obras Escolhidas III. São Paulo: Brasiliense, 1989.

BRESCIANI, Maria Stella. "Permanências e ruptura no estudo das cidades". In: FERNANDES, Ana; GOMES, Marco Aurélio (org.) Cidade e História. Salvador: UFBA/ANPUR, 1992.

CALVINO, Ítalo. As Cidades Invisiveis. $12^{\circ}$ ed. São Paulo: Companhia das Letras, 1990.

CERTEAU, Michel De. A Invenção do Cotidiano: Morar, Cozinhar. Petrópolis: Vozes, 2008.

COUCEIRO, Sylvia Costa. "A sedução da noite nos cafés do Recife dos anos 1920: entre prazeres e transgressões”. XXIV SIMPÓSIO NACIONAL DE HISTÓRIA. 7, 2007, São Leopoldo. Anais. São Leopoldo: ANPUH, 2007. v. CD ROM.

FREYRE, Gilberto. Guia Prático, Histórico e Sentimental da Cidade do Recife. Rio de Janeiro: José Olympio, 1934.

FREYRE, Gilberto. Livro do Nordeste. São Paulo: Global, 2004.

GOMES, Ângela de Castro (org.) Escrita de si, Escrita da História. Rio de Janeiro: FGV, 2004.

LEITE, Rogerio Proença. Contra-usos da Cidade: Lugares e Espaço Público na Experiência Urbana Contemporânea. Campinas: Unicamp; Aracajú: UFS, 2007.

MICELI, Sergio. Intelectuais à Brasileira. Rio de Janeiro: Cia das Letras, 2001.

MOTA, Mauro. História em Rótulos de Cigarros. 20 ed. Recife: Instituto Joaquim Nabuco de Pesquisa Sociais, 1971.

MOURA, Carlos André Silva de. "Fé, saber e poder: os intelectuais entre a Restauração Católica e a política no Recife $(1930$ - 1937)”. 2010. 161 p. Dissertação (Mestrado em História Social da Cultura Regional). Programa de Pós-graduação em História Social da Cultura Regional, Universidade Federal Rural de Pernambuco, Recife, PE, 2010.

PARAÍSO, Rostand. A Esquina do Lafayette e Outros Tempos do Recife. Recife: Rostand Paraíso, 2001. 
A Velha Rua Nova e Outras Histórias. Recife: Bagaço, 2002. . Livros, Livreiros, Livrarias. Recife: Bagaço, 2006.

RIO, João. A Alma Encantadora das Ruas. São Paulo: Cia das Letras, 2008.

Royal. Diario de Pernambuco, Recife, p. 09, 01 abr. 1934.

SANTOS, Mário Ribeiro dos. Trombones, Tambores, Repiques e Ganzás: a Festa das Agremiações Carnavalescas nas Ruas do Recife (1930-1945). Recife: SESC, 2010.

SEIGEL, Jerrold. Paris Boêmia: Cultura, Politica e os Limites da Vida Burguesa. 1830 - 1930. Porto Alegre: L\&PM, 1992.

SETTE, Mário. Arruar: Histórias Pitorescas do Recife Antigo. $2^{\circ}$ ed. Rio de Janeiro: Livraria - editora da Casa do Estudante do Brasil, 1952.

SETTE, Mario. "Os antigos cafés do Recife". Diario de Pernambuco, Recife, p. s/n, 05 fev. 1933.

Um grande emporio industrial. Ilustração Brasileira, Recife, p. 199, 24 jun. 1924. 